\title{
Ovulation induction and gamete transport in the female tract of the musk shrew, Suncus murinus
}

\author{
J. M. Bedford ${ }^{1}$, T. Mori ${ }^{2}$ and S. Oda ${ }^{3}$ \\ ${ }^{1}$ Depts of Obstetrics and Gynecology and Cell Biology and Anatomy, Cornell University Medical College, \\ New York, NY 10021, USA; ${ }^{2}$ Zoological Laboratory, Faculty of Agriculture, Kyushu University, \\ Fukuoka 812, Japan; and ${ }^{3}$ Laboratory of Animal Management, School of Agricultural Sciences, \\ Nagoya University, Nagoya 464, Japan
}

\begin{abstract}
The musk shrew Suncus murinus was studied with regard to induction of ovulation, the genesis and role of the vaginal copulation plug, and the behaviour of gametes and embryos within the Fallopian tube. Ovulation occurred about $15 \mathrm{~h}$ after ejaculation, which required a mean of 5.2 (range 2-10) intromittent thrusts. Since ovulation occurred also after five thrusts without ejaculation, and after ejaculation without plug formation or sperm deposition, the primary stimulus for this seemed to be the thrust of the penis, the glans of which was covered by a dense field of spines. Neither vasectomized nor prostatectomized males formed a plug at ejaculation, and in the latter case the mean number of spermatozoa reaching the isthmus of the Fallopian tube, the number at the ampullary fertilization site and the rate of fertilisation were lower than in females mated to normal males. Thus both the vesicular gland on the vas deferens and the prostate are essential for formation of the copulation plug, which appears to enhance sperm transport within the female tract. At ejaculation, $\leq 10^{6}$ spermatozoa were incarcerated by the plug in the anterior vagina for 6-7 h, by which time a maximal population of several hundred had become established in posterior crypts of the isthmus of the Fallopian tube as small groups of free languidly moving spermatozoa. It remains to be established whether oviductal crypts in this and other shrews have a storage function for spermatozoa or sequester spermatozoa and so regulate the number that reach the fertilization site. Very few spermatozoa reached the ampulla of Suncus. Generally, only one or two spermatozoa had reached the ampulla by $4-5 \mathrm{~h}$, and often less than ten had done so by 5-13 h after ovulation. As a probable correlate, few eggs were penetrated during the first $5 \mathrm{~h}$, with a frequent delay of 10-13 h before most eggs were fertilized. Thereafter, unfertilized eggs were transported through the oviduct at the same rate as developing embryos, which entered the uterus about $85 \mathrm{~h}$ after ovulation at the 32-cell stage. There were highly significant differences between the larger KAT/SK strains and smaller OK strain with regard to Fallopian tube length (mean $6.9 \mathrm{~mm}$ versus $9.7 \mathrm{~mm}$ ), as well as the rates of hCG-induced ovulation (5.6 versus 3.25 ) and of unilateral ovulation $(6 \%$ versus $50 \%)$.
\end{abstract}

\section{Introduction}

Our understanding of and ability to manipulate the events of conception have increased markedly as a result of intensive research. However, because the focus of research on conception has been primarily on humans and several laboratory and domestic animals, it remains difficult to appreciate the adaptive significance and underlying function of many of the novel features of conception that have appeared during the evolution of mammals. Important examples in the male include a critical dependence of sperm maturation on the epididymal environment, an androgen and lower temperature-regulated epididymal system of sperm storage, accessory gland development,

Received 9 November 1996. adoption of the scrotal state and, not least, a unique design of the sperm head. Equally difficult to understand in the female is the adaptive significance of sperm capacitation, the postovulatory persistence of the cumulus oophorus, the exaggerated form of the zona pellucida, and the unusual mode of gamete fusion unique to eutherian mammals.

One group that seems important to consider in pursuing these questions is the Insectivora, which exhibit several primitive anatomical features thought to link them to the progenitors of present-day Eutheria (Carroll, 1988). However, very little is known about their gamete function and conception, in part because of the difficulty of maintaining and manipulating insectivores in a laboratory settting. One among a few exceptions is Suncus murinus, the Asian or house musk shrew, which will mate readily and rear young in laboratory 
conditions (Dryden, 1969, 1975). However, gametes of Suncus possess several unusual features, among which are a giant stable acrosome, the small number of spermatozoa ejaculated, and a compact matrix-free cumulus oophorus of long life that resists hyaluronidase (Bedford et al., 1994). Another unusual feature in Suncus is a system of crypts extending throughout the isthmus of the oviduct. Sperm storage within oviductal crypts occurs in various ways in several non-mammalian vertebrates (Parkes, 1960) and in some marsupials (Rodger and Bedford, 1982; Selwood and McCallum, 1987; Breed et al., 1989), but tubal sperm crypts do not appear to have been reported among other Eutheria, except those at the uterotubal junction in the cow (Hunter, 1995). Fortunately, the distribution, behaviour, and interaction of gametes within the small oviduct of this shrew can be observed with differential interference (Nomarski) optics in transilluminated light. In addition, the ability to time ejaculation and the fact that ovulation is induced by coitus or by hCG injection permits direct tracking of the transport of both its spermatozoa and eggs. Such an approach has been used here to analyse the stimulus for ovulation, copulation plug formation, the transport of spermatozoa to and within the oviduct, and their interaction with the cumulus oophorus and the egg. At the same time the rates at which unfertilized oocytes and embryos pass through the oviduct were compared.

\section{Materials and Methods}

The animals were reared either at Kyushu University or more usually at the Laboratory of Animal Management, School of Agricultural Sciences, Nagoya University. They were housed in individual cages containing a shelter, and water and food were available ad libitum. Unless otherwise stated, the results refer to females of a large strain with a mean body mass of $50.8 \mathrm{~g}$ (range $30-78 \mathrm{~g} ; n=125$ ) originating from shrews caught in Katmandu, Nepal, and in central India (KAT), together with a few similar descendent hybrids of animals from Katmandu and from Sri Lanka (SK), with a mean body mass of $54.5 \mathrm{~g}$ (range $47-65 \mathrm{~g} ; n=9$ ). In addition, a few smaller animals used were collected in Okinawa (OK) (mean body mass $33.4 \mathrm{~g}$, range $29-41 \mathrm{~g} ; n=13$ ), or were descendent hybrids of animals from Japan and Indonesia (MI) (mean body mass $37.6 \mathrm{~g}$, range $33-46 \mathrm{~g} ; n=15$ ). The males of each strain were larger than the respective females; those of the KAT strain ranged up to $125 \mathrm{~g}$. A group of 24 sperm-positive predominantly KAT males with good libido was used for mating, none more than once every 4 days.

\section{Mating}

Females introduced into the male's cage were observed for potential receptivity (e.g. tail wagging). Copulation was preceded typically by $0.25-3.0 \mathrm{~h}$ periods of male pursuit, fighting interactions, and multiple mounts (Dryden, 1969; Rissman, 1987). Females were usually separated from the male about 15 min after ejaculation, and examined at various times from $1 \mathrm{~h}$ to $101 \mathrm{~h}$ later. However, in one additional group of six females each was left with the male for $25-28 \mathrm{~h}$ after an observed ejaculation, and in another such group, each female was allowed to mate successively with three males at intervals of several hours before ovulation, with examination at $25-28 \mathrm{~h}$ after the first ejaculation.

\section{Ovulation induction and copulation plug formation}

On the basis of previous experience (Dryden, 1969; Bedford et al., 1994), ovulation was induced by mating, or in selected females by 20-30 units of hCG (Pregnyl: Organon), given i.p. For analysis of the factors that induce ovulation, each of six females was separated from the male after five intromittent thrusts, but before ejaculation. Analysis of the male accessory organs that contribute to the formation of the copulation plug involved vasectomy or prostatectomy. For vasectomy, two fertile males were anaesthetized with sodium pentobarbital $\left(0.06 \mathrm{mg} \mathrm{ml}^{-1}\right)$, and subjected to a low midline laparotomy. Ligatures of $7 \times 0$ braided silk were placed bilaterally around the vas deferens between the terminus and the prominent vesicular gland that envelops the mid-section of the vas deferens in shrews (Kowalska-Dyrcz, 1966; Bedford et al., 1994), serving to exclude spermatozoa and secretions of the vesicular gland from the ejaculate. Prostatectomy involved bilateral excision of the major dorsal lobe of the prostate (Kitoh et al., 1985), leaving a small ventral remnant on both sides. After introduction of about $0.2 \mathrm{ml}$ of a crystalline penicillin solution into the peritoneal cavity, the laparotomy site was closed with $7 \times 0$ monofilament nylon.

As a possible factor in the induction of ovulation, the surface of the glans penis was studied under a light microscope and photographed in reflected light. The glans was also prepared for scanning electron microscopy (SEM) by washing and then fixation for $24 \mathrm{~h}$ in $3 \%(\mathrm{v} / \mathrm{v})$ glutaraldehyde in cacodylate buffer, and then the epidermis was shaved off with a razor blade. After dehydration in a series of alcohols followed by acetone, pieces of this were then affixed to aluminium foil, sputtered with gold, and examined in a JEOL JSM-5200 scanning electron microscope.

\section{Examination of the female reproductive tract and the gametes within it}

At various times after mating or injection of hCG, females were killed with ether and weighed, and then the whole reproductive tract (Fig. 1) was exposed immediately and the vagina was assessed for the presence of a plug. Plugs were fixed in situ or free in $3 \%$ glutaraldehyde in $0.2 \mathrm{~mol}$ sodium cacodylate $\mathrm{I}^{-1}$ buffer $\left(4^{\circ} \mathrm{C}, \mathrm{pH} 7.4\right)$, washed thoroughly in buffer, dehydrated through an ethanol series and embedded in Kulzer Technovit 7100 methacrylate resin. Sections (about $1.5 \mu \mathrm{m}$ ) were doubly stained with haematoxylin and eosin, or toluidine blue $(0.5 \% \mathrm{w} / \mathrm{v})$.

For total sperm counts, the vaginal content was aspirated or scraped into a known volume of medium. At different times after mating the uterine content was squeeze-stripped with fine forceps and examined for spermatozoa, but occasional uterine horns were flushed via a 31 gauge needle with about $0.2 \mathrm{ml}$ of Dulbecco's modified Eagle's medium (DMEM: Gibco BRL, Tokyo) containing BSA ( $3 \mathrm{mg} \mathrm{ml}^{-1}$ ), to obtain spermatozoa which were counted with an improved Neubauer 


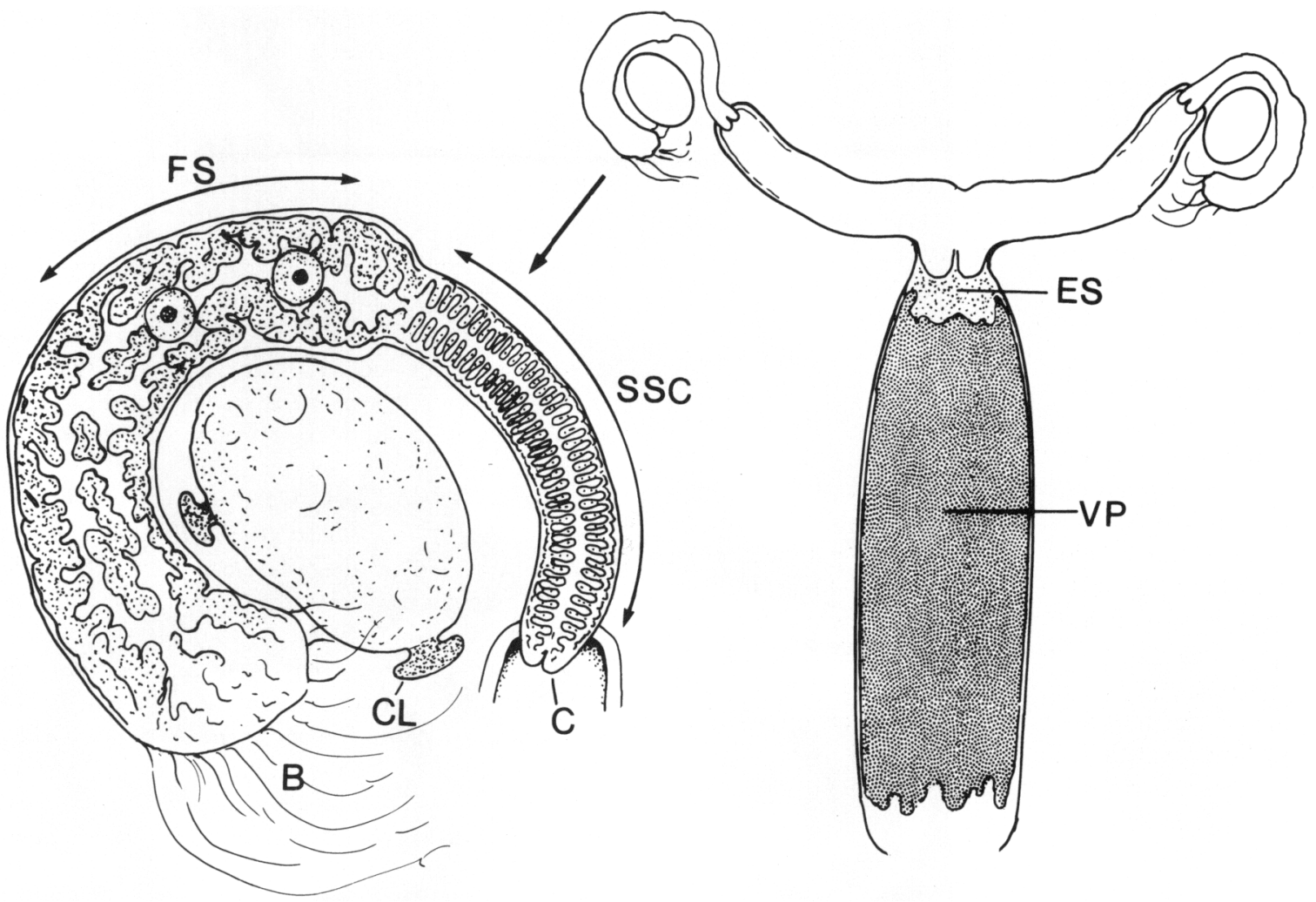

Fig. 1. The female reproductive tract in the musk shrew, Suncus murinus, with enlargement of the Fallopian tube. B: remnant folds of ovarian bursa extending from the ampulla; C: colliculus tubaricus; CL: early corpus luteum; ES: pool of ejaculated spermatozoa; FS: fertilization site; SSC: isthmic sperm crypts; VP: vaginal plug.

haemocytometer. Fallopian tubes were quickly dissected free of mesosalpinx and ovarian bursa using microscissors and very fine forceps, and preovulatory follicles or the typically mushroom-like ovulation points were counted on the ovaries. During dissection, care was taken to include the colliculus tubaricus (Fig. 1), ensuring that all tubal spermatozoa would be accounted for. The resting length of straightened oviducts was measured directly, and then oviducts were mounted on a warm wax-spot slide in a warm drop of DMEM-BSA. After slight compression they were examined using a differential interference contrast (DIC) microscope for the location and appearance of spermatozoa, of eggs with or without cumulus, or of embryos.

Two oviducts fixed in $3 \%$ glutaraldehyde on a slide were examined for spermatozoa within isthmic crypts using a Nikon confocal laser microscope. Otherwise, after whole-mount examination for the distribution and state of gametes or embryos the oviduct was divided at the isthmo-ampullary junction (Fig. 1). The content of each segment was then stripped with microforceps into a drop of medium on a slide, leaving only a serosal shell with essentially no residual spermatozoa evident, and examined with phase contrast optics for the number and state (motility, acrosome status) of the spermatozoa. After release from cumulus oophorus by needle dissection, eggs mounted on a wax-spot slide were assessed in a phase contrast microscope, first in the fresh state, and then after fixation in acetic alcohol (1:3) and staining in $0.75 \%(\mathrm{w} / \mathrm{v})$ lacmoid in $45 \%(\mathrm{v} / \mathrm{v})$ acetic acid.

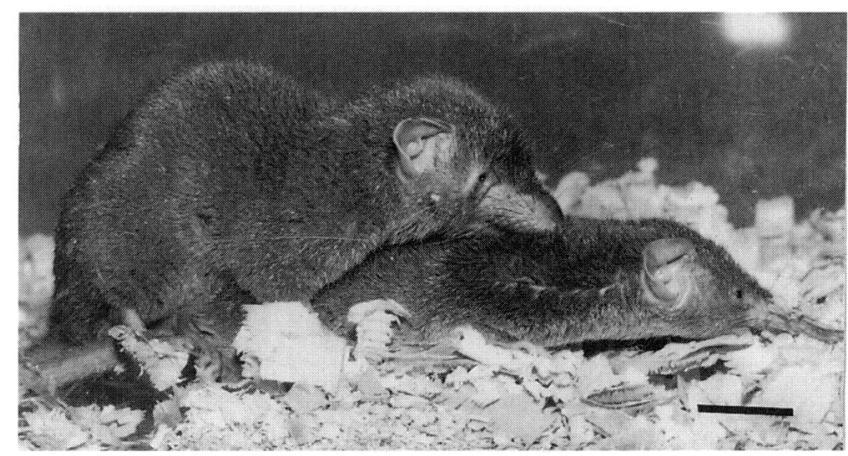

Fig. 2. The moment of intromission during mating in the (KAT) musk shrew, Suncus murinus. Printed from a colour negative on Kodak 'Panalure' high contrast paper. Scale bar represents $1.65 \mathrm{~cm}$.

Differences in ovulation rates and Fallopian tube lengths between KAT and OK strains were assessed using the unpaired $t$ test.

\section{Results}

Vaginal copulation plug

Ejaculation was preceded by a variable number of deep intromittent penile thrusts (Fig. 2). Ejaculation itself was signalled by a prolonged ( $5-7 \mathrm{~s}$ ) deep intromission, then falling of 
(a)

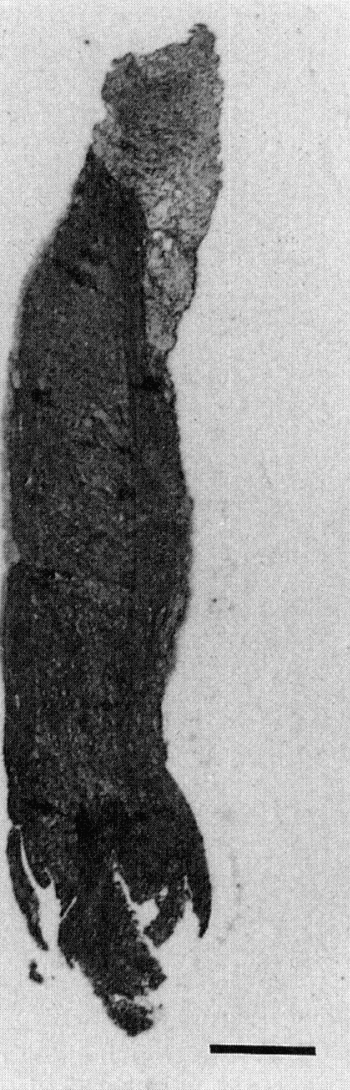

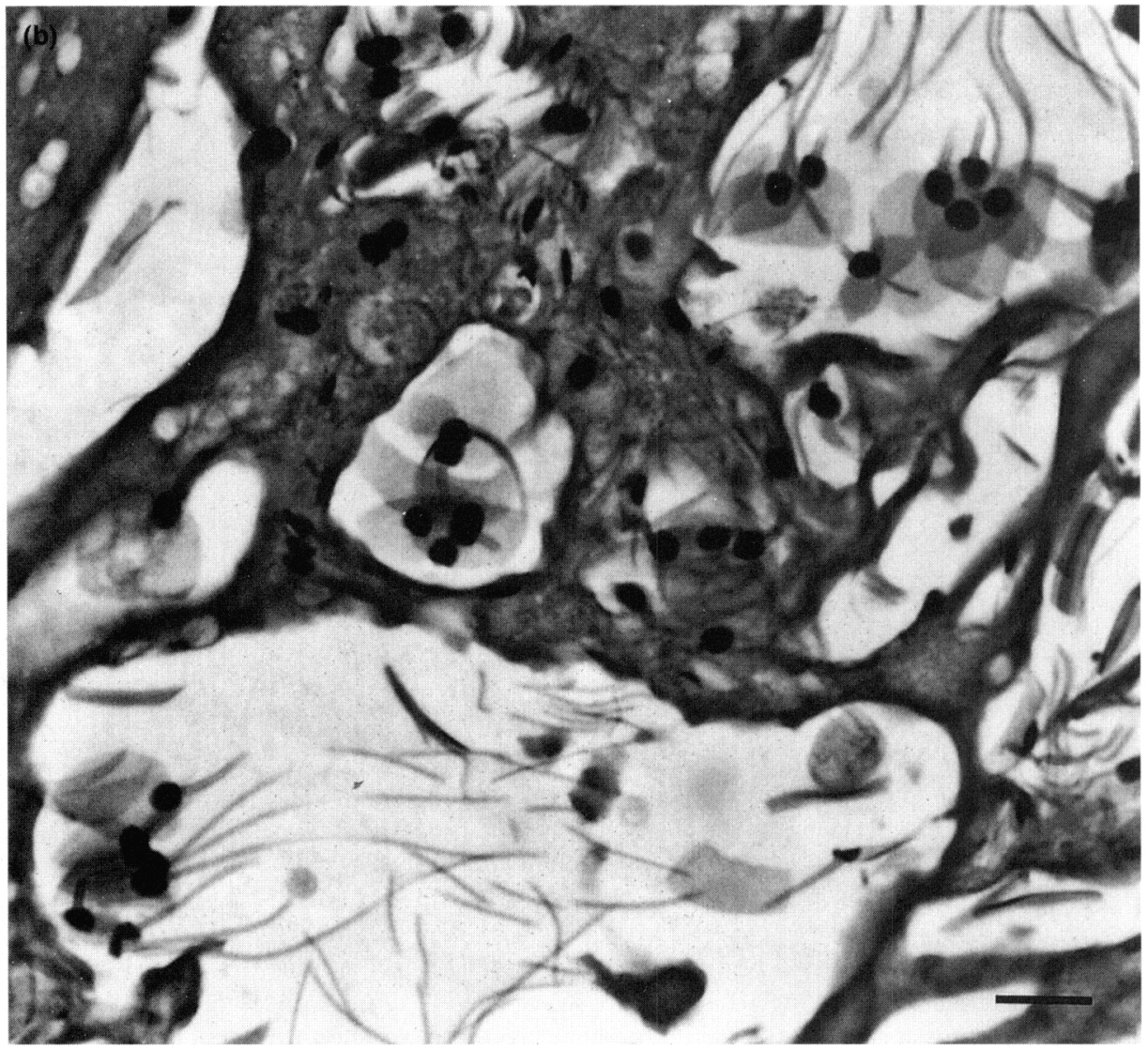

Fig. 3. (a) Longitudinal section of a vaginal plug fixed in situ $<1 \mathrm{~h}$ after ejaculation, and then removed. On top of the plug sits the less dense mass of ejaculated spermatozoa, around which co-mingled secretions formed a loculated mesh upon fixation. Glutaraldehyde fixation. Scale bar represents $1.54 \mathrm{~mm}$ (b). Ejaculated spermatozoa within the peri-cervical sperm mass in (a) are characterized by round dense nuclei and pale leaf-shaped giant acrosomes, interspersed within loculi of the surrounding secretion. Glutaraldehyde fixation. Scale bar represents $12.5 \mu \mathrm{m}$.

Table 1. Distribution of spermatozoa in the female tract of the musk shrew, Suncus murinus, at different times after mating

\begin{tabular}{|c|c|c|c|c|c|c|c|c|c|}
\hline \multirow[b]{2}{*}{$\begin{array}{l}\text { Time after } \\
\text { coitus }(h)\end{array}$} & \multirow[b]{2}{*}{$\begin{array}{l}\text { Number of } \\
\text { females }\end{array}$} & \multirow[b]{2}{*}{$\begin{array}{l}\text { Copulation } \\
\text { plug }\end{array}$} & \multirow[b]{2}{*}{$\begin{array}{l}\text { Spermatozoa } \\
\text { in vagina }\end{array}$} & \multirow[b]{2}{*}{$\begin{array}{l}\text { Spermatozoa } \\
\text { in uterus }\end{array}$} & \multicolumn{2}{|c|}{ Isthmus } & \multicolumn{2}{|c|}{ Ampulla } & \multirow{2}{*}{$\begin{array}{c}\text { Percentage } \\
\text { of ova } \\
\text { fertilized }^{b}\end{array}$} \\
\hline & & & & & $\begin{array}{c}\text { With } \\
\text { spermatozoa }\end{array}$ & $\begin{array}{l}\text { Mean number } \\
\quad \text { (range) }\end{array}$ & $\begin{array}{c}\text { With } \\
\text { spermatozoa }\end{array}$ & $\begin{array}{l}\text { Mean number } \\
\quad \text { (range) }\end{array}$ & \\
\hline$\leq 1$ & 8 & $8 / 8$ & ++++ & $7 / 8$ & 0 & 0 & 0 & 0 & - \\
\hline $6-7$ & 8 & $7 / 8$ & -+++ & $8 / 8$ & $12 / 12$ & $233(19-509)$ & $5 / 12$ & $2.2(0-13)$ & - \\
\hline $14-15$ & 9 & $1 / 9$ & ---+ & $9 / 9$ & $9 / 9$ & $371(49-591)$ & $6 / 10$ & $1.2(1-3)$ & - \\
\hline $17.5-19$ & 9 & $0 / 9^{c}$ & ---+ & $9 / 9$ & $16 / 16$ & $158(25-478)$ & $8 / 17$ & $1.4(0-5)^{\mathrm{d}}$ & 13.8 \\
\hline $20-22$ & 9 & o/9 & ---- & $9 / 9$ & $17 / 17$ & $318(17-1000)$ & $16 / 17$ & $6.5(0-21)^{e}$ & 53.8 \\
\hline $25-28$ & 9 & $0 / 9$ & ---- & $9 / 9$ & $17 / 17$ & $270(25-997)$ & $16 / 17$ & $9.2(0-22)$ & 83.3 \\
\hline
\end{tabular}

ancludes spermatozoa within cumulus and eggs.

${ }^{\mathrm{b}}$ Assessments on 6 females per time period.

${ }^{\circ}$ Remnants of plug in one female.

${ }^{\mathrm{d}}$ Excludes one atypical outlier (75 spermatozoa) on non-ovulating side.

Excludes three atypical outliers $(49,89,29$ spermatozoa) on non-ovulating sides.

the male to one side, followed by harassment of the female for some minutes (e.g. biting at the neck region) with no further attempts to mount. A copulation plug (Fig. 3a) occupied the vagina in all of eight females at about $1 \mathrm{~h}$ after mating, and was still intact or largely so in seven of eight females examined 6-7 h after coitus (Table 1). The pericervical space anterior to the plug was occupied by concentrated active spermatozoa (Fig. 3b). By 14-19 h the plug was no longer present in 17 of 18 females, all of which had very few or no spermatozoa in the vagina. The finding of only occasional spermatozoa in crosssections of its matrix suggests that the plug is formed after vaginal deposition of the sperm-rich fraction of the ejaculate. In 

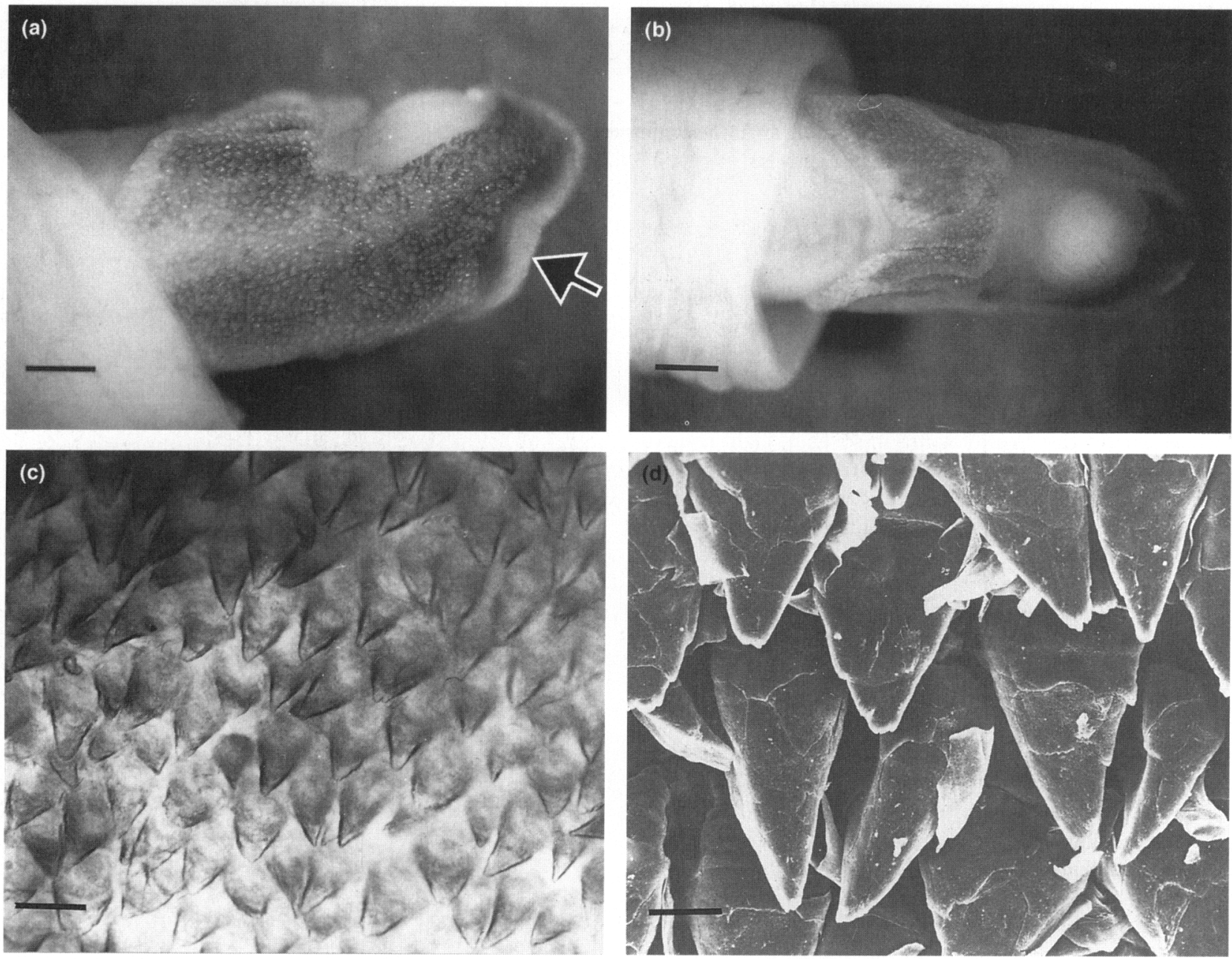

Fig. 4. (a) Lateral view, and (b) dorsal view of the glins penis of Suncus murinus. The glans is underlain by a haematic sinus and presents as a sculpted 'galea' covered by a field of spines, many of which point toward the base of the penis. A broad arrow indicates the location of the external meatus. (c) A field of spines on the surface of the unfixed glans peris, seen in reflected light. (d) Spines on the surface of the glans penis are covered with 'scales' of flat epithelial cells; glutaraldehyde fixation, SFV. Scale bars in (a) and (b) represent $800 \mu \mathrm{m}$, in (c) $80 \mu \mathrm{m}$, and in (d) $20 \mu \mathrm{m}$.

contrast to normal males, neither of the vasectomized males nor any of the three prostatectomized males formed a vaginal plug on ejaculation.

\section{Ovulation}

Ovulation had occurred in only one of nine females examined $14-15 \mathrm{~h}$ after coitus, and had begun in two of five females by $14.75 \mathrm{~h}$ after treatment with hCG. In the KAT/SK strains, the $78.2 \%$ of 64 females that had ovulated $\geq 17 \mathrm{~h}$ after coitus produced $5.16 \pm 0.21$ (SEM) oocytes per female. After treatment with hCG, ovulation had occurred in 51 of 52 such females examined $\geq 16.75 \mathrm{~h}$ later, with a mean of $5.6 \pm 0.44$ oocytes. On the basis of these and earlier observations, $15.5 \mathrm{~h}$ was chosen as an appropriate baseline for computing the timing of fertilization and egg and embryo transport.

There was no difference in the number of eggs produced by the right and left ovaries after coitus- or hCG-induced ovulation. In the case of KAT females, unilateral ovulation occurred in $21 \%$ of 49 coitus-induced, and in only $6 \%$ of 52 hCG- induced ovulations. By contrast, among OK females $(n=12)$ hCG resulted in a $50 \%$ incidence of unilateral ovulation, with a significantly lower mean of 3.25 oocytes (range 1-5) $(P<0.0001)$. Again, during unilateral ovulation there was no bias toward one or other ovary.

Twenty normal matings that induced ovulation involved a mean of 5.2 intromittent thrusts including the thrust associated with ejaculation (range: 2-10: median: 5). The stimulus required for ovulation appeared to come primarily from penile thrusts alone. It did not depend on the formation of a copulation plug as six eggs were ovulated on both occasions when a female was mated to one or other vasectomized male, and ovulation occurred in six of eight matings with the prostatectomized males (mean 4.5 oocytes), although none formed copulation plugs. Finally, when six receptive females were separated after five deep intromittent penile thrusts but before ejaculation, and so before plug formation, three had ovulated a mean of three eggs each on examination $21 \mathrm{~h}$ later.

In considering the stimulation provided by the penis, the glans presented as a sculpted rough-surfaced area laterally and 
as a band around the anterior border above the external meatus, behind which was a smooth-surfaced circular dorsal depression (Fig. 4a, b). The surface was characterized by sharp spines (Fig. 4c), each covered by 'scales' of flattened epithelial cells (Fig. 4d). The red of the glans reflected an underlying haematic sinus supplied by obvious lateral vessels.

\section{Sperm transport}

In five females the number of spermatozoa incarcerated by the plug within the pericervical cavity of the anterior vagina $\leq 1 \mathrm{~h}$ after ejaculation, thus largely reflecting the number in the ejaculate, were, respectively, 1.0, $0.9,0.85,0.5$ and $0.04 \times 10^{6}$ (Table 1). A few motile spermatozoa were recovered from the uterine cavity by $45 \mathrm{~min}$ after coitus in seven of eight females, but no more than 5000-10000 were recovered from either uterine horn. Histological sections also served to emphasise the major difference in sperm concentrations between the anterior vagina and lower uterus. It can be inferred from those progressing through the cervical canal (Fig. 5a, b) that Suncus spermatozoa advance from the vagina to the uterus as individual cells, rather than en masse, depending for this on their motility.

The length of the Fallopian tube varied according to the strain of musk shrew. In the smaller OK strain of about $33.5 \mathrm{~g}$ body mass, the mean resting length of the excised oviduct was $9.68 \mathrm{~mm}$ (range $8.0-11.0 \mathrm{~mm}: n=14$ ), significantly longer $(P<0.0001$ ) than the mean of $6.9 \mathrm{~mm}$ (range 6.0-7.8: $n=25$ ) in the larger (about $52.0 \mathrm{~g}$ ) KAT/SK females, in which the isthmus was noticeably shorter. The Fallopian tube is characterized by a colliculus tubaricus that protrudes into the uterus (Figs $I$ and 6a), and by deep crypts arrayed throughout the isthmus (Figs 1 and 7a). No sperm colonization of the isthmus had occurred by 45-60 min after coitus, although spermatozoa were gathered at its opening in one female. However, motile spermatozoa were regularly observed entering the colliculus at 6-7 h (Fig. 6b), and others could be seen then with DIC optics and the confocal microscope (Figs $7 \mathrm{~b}, \mathrm{c}$ ), as small groups of up to ten within posterior isthmic crypts of all oviducts. The spermatozoa generally displayed a slow languid movement within the crypts and were not adherent to the epithelium. Before and after ovulation, the isthmic population of spermatozoa was virtually confined to crypts in the posterior (uterine) half, and it was rare to see any in the anterior isthmus closer to the IAJ.

At $6-7 \mathrm{~h}$ an average of 200-300 spermatozoa was recovered from the isthmus, and this number was maintained for up to $25-28 \mathrm{~h}$ after coitus (Table 1 ). By contrast, spermatozoa were recoverable from only about half of the ampullary segments at all times up to $3.5 \mathrm{~h}$ after ovulation, and then only one or two per ampulla. In one exceptional case at $19 \mathrm{~h}$ after

Fig. 5. (a) Section through anterior vagina (V), the relatively simple cervix $(\mathrm{C})$, and lower uterus $(\mathrm{U})$ in Suncus murinus about $1 \mathrm{~h}$ after coitus. (b) Higher magnification through the cervix illustrating a group of spermatozoa progressing in line through the narrow cervical canal. Haematoxylin and eosin. Scale bar in (a) represents $50 \mu \mathrm{m}$, and in (b) $10 \mu \mathrm{m}$. coitus the ampulla yielded 75 intact motile spermatozoa, but in this instance there was no ovulation from the ipsilateral ovary. At $20-22 \mathrm{~h}$ after coitus the ampulla yielded a moderately
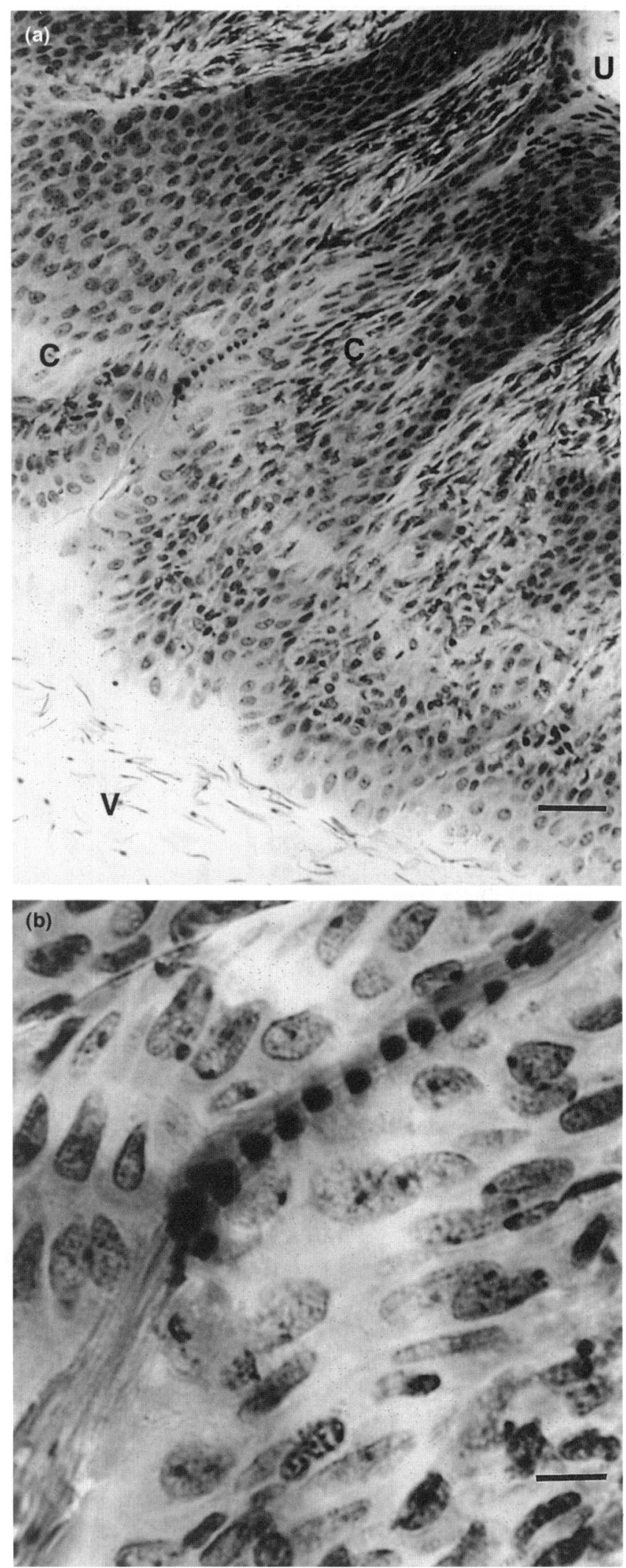

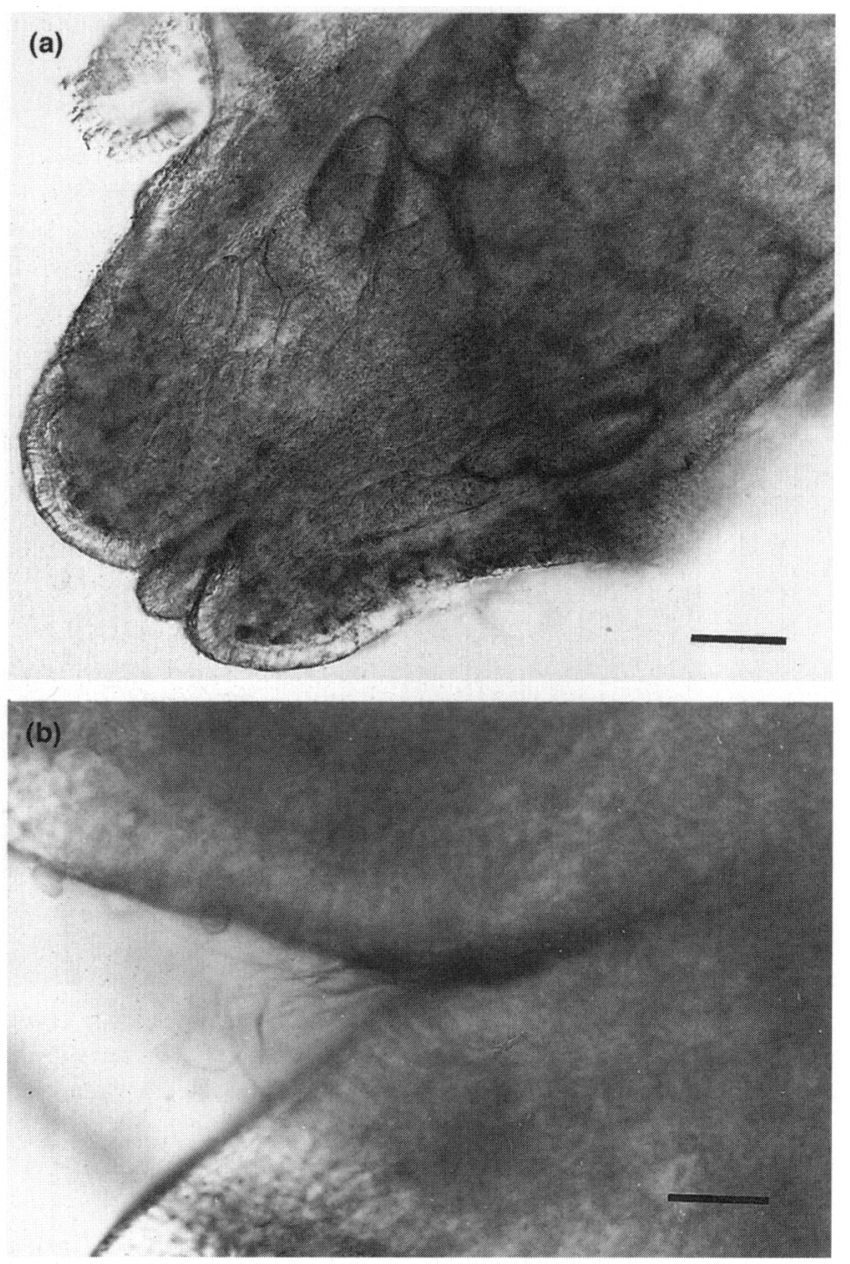

Fig. 6. (a) Lower isthmus and colliculus tubaricus of the Fallopian tube, slightly compressed to partly reveal the three lips of the colliculus and the lower limits of isthmic sperm crypts. Differential interference microscopy (DIC). Scale bar represents $130 \mu \mathrm{m}$. (b) Several spermatozoa clustered between the lips of the colliculus at the entrance to the isthmic canal $7 \mathrm{~h}$ after coitus. Printed from a colour negative on Kodak 'Panalure' high contrast paper. DIC. Scale bar represents $45 \mu \mathrm{m}$.

higher mean of 6.5 spermatozoa by then, and again three of the four highest ampullary counts (87, 49 and 29 spermatozoa) were associated with a failure of the ipsilateral ovary to ovulate. A similar general picture prevailed at 25-28 h after coitus (Table 1). Thereafter, lower isthmic (range 8-47) and ampullary (range 0-3) numbers were recorded at 38-47 h after coitus, but the few spermatozoa remaining in crypts were still motile.

Because these data were obtained from females separated after one ejaculation, studies were performed with two further groups, each of five females. In one group mated females were left with males to provide the opportunity for further copulation, a mean of 326 isthmic spermatozoa (range 45-1165), and of 17 ampullary spermatozoa (range 0-61) were recovered at $25-28 \mathrm{~h}$, and $81.5 \%$ of their eggs were fertilized then. In a second group in which each female was mated to three males before ovulation, similar means of 322 (range 17-1400) and 20 (range 4-42) spermatozoa were recovered at 25-28 h, with an overall fertilization rate of $92 \%$. The figures were comparable to those obtained then with separation soon after one ejaculation.

Although the three prostatectomized males failed to form a copulation plug, each ejaculated spermatozoa and fertilized some eggs. Despite the absence of a plug, some spermatozoa had colonized isthmic crypts $25-28 \mathrm{~h}$ after coitus in seven of eight matings, but a mean of only 25.5 spermatozoa (range 0-94) was recovered at that time from the isthmus: much lower than the mean of 322 recovered then after mating to normal males. Although a comparably lower mean of 3.75 spermatozoa (range $0-10 ; n=12$ ) was recovered per ampulla, in 10 of 12 oviducts examined all the ampullary spermatozoa were within a cumulus or within an egg in five of the six females that had ovulated, and $68 \%$ of 25 recovered eggs were fertilized.

\section{The timing of fertilization}

Only $13.8 \%$ of the eggs were penetrated by $2-4 \mathrm{~h}$ after ovulation, and only half $(53.8 \%)$ by $5-7 \mathrm{~h}$ after ovulation (Table I). Although most $(83.3 \%$ ) had been fertilized by 10-13 h after ovulation, some displayed only decondensing sperm nuclei then - a sign of their recent penetration.

\section{Oocyte and embryo transport}

After slight compression of the transilluminated Fallopian tube, the precise position of eggs and embryos could be seen clearly with DIC optics (Figs $8 \mathrm{a}, \mathrm{b}$ ). Within only $2 \mathrm{~h}$ of coitalor hCG-induced ovulation ( $n=16$ oviducts), unfertilized eggs in cumulus had often moved down the ampulla to lie close to the IAJ, and all were located there in 12 females examined between 15 and $41 \mathrm{~h}$ after ovulation. In pilot observations on two mated females, similarly, two- to four-cell embryos without cumulus were in the lower ampulla about $32 \mathrm{~h}$ after ovulation, but all eggs and embryos had moved down to the isthmus in six females by $49-75 \mathrm{~h}$ after ovulation. By $85 \mathrm{~h}$, in two unmated and two mated females their respective eggs and embryos were distributed between the lower isthmus and uterus. Lacmoid staining showed that these embryos were entering the uterus at the 32-cell stage. These pilot observations provided the basis for a formal comparison of the rate of transport of unfertilized eggs and of embryos, using two endpoints: passage across the IAJ at $48 \mathrm{~h}$ after ovulation, and from the lower isthmus into the colliculus or uterus at $85 \mathrm{~h}$ after ovulation. Both unfertilized eggs and embryos were distributed around the IAJ at $48 \mathrm{~h}$ after ovulation (Fig. 8a), and by $85 \mathrm{~h}$, both unfertilized eggs and 32-cell embryos were either positioned in the lower isthmus or were emerging from the colliculus into the uterine cavity (Table 2).

\section{Discussion}

The present results confirm previous observations that ovulation in Suncus takes place consistently about $15 \mathrm{~h}$ after hCG injection, and is induced then generally, though not always, by a single mating (Dryden, 1969; Clenendon and Rissman, 1990; Bedford et al., 1994). For KAT/SK females, the major strains used here, the ovulation rate following a single ejaculation was $78.2 \%$. However, the results indicate that neither the 

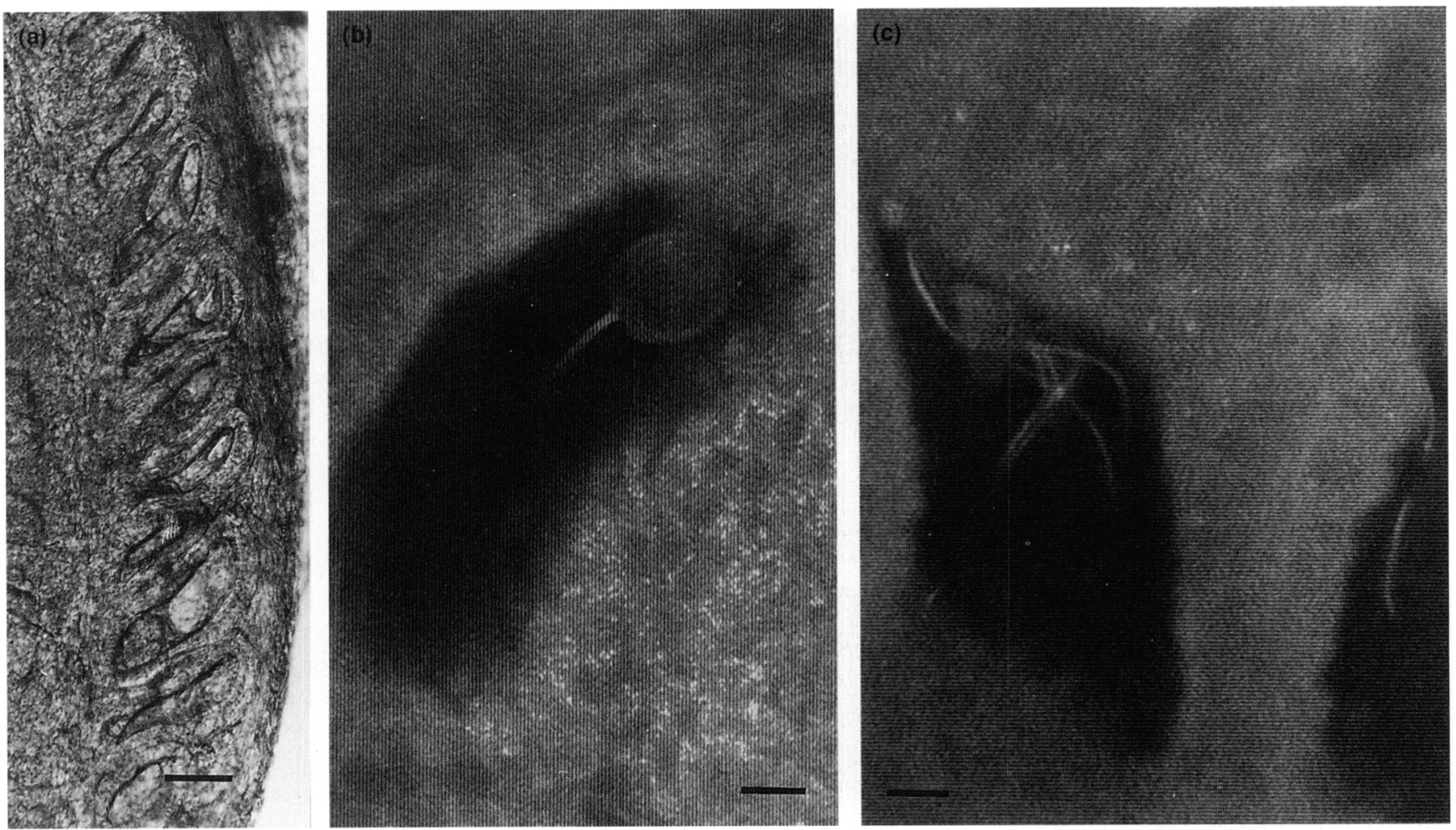

Fig. 7. (a) One side of the oviduct isthmus in a living whole mount preparation. Slight flattening beneath the cover glass reveals the deep crypts which are arrayed throughout the isthmus. Differential interference microscopy (DIC). Scale bar represents $150 \mu \mathrm{m}$. (b) and (c) Two views in the confocal laser microscope of Suncus murimus spermatozoa within isthmic crypts, $22 \mathrm{~h}$ after coitus. Glutaraldehyde fixation; scale bars represent $10 \mu \mathrm{m}$

deposition of a copulation plug nor of spermatozoa are important for ovulation. Rather, a primary factor appeared to be the vaginal stimulation evoked by penile intromissions, and it is possible that the spines on the glans penis could have a role. Penile spines have been described in cats (Aronson and Cooper, 1969), which are induced ovulators, and for rats (Sachs ct al., 1984) where coitus stimulates not only the secretion of prolactin required for a functional corpus luteum, but also ovulation in rats 'converted' by neurosuppressants (see Milligan, 1982). Such spines are evident also in certain bats (Pteropus giganteus: Murthy and Vamburker, 1978; Monopterus planiceps: Krutzsch and Crichton, 1987), the former at least being cited as likely to be an induced ovulator (Milligan, 1982). Nonetheless, the relative importance of penile spines has been a matter for debate. Zarrow and Clark (1968) drew strong inferences from their presence in a variety of induced ovulators, whereas Milligan (1982) later expressed reservations about this interpretation. Although such spines could maximize penile stimulation of the vagina in Suncus, the present observations certainly do not prove this. Indeed, since only three of six females ovulated in response to five intromissions alone, compared with all of 13 receiving two to five intromissions with ejaculation, either the final prolonged thrust that accompanies ejaculation and or the harassment of the female that follows may have some reinforcing role.

The failure to deposit a plug after removal of the major lobes of the prostate or after vasectomy in the terminal part of the vas deferens indicates that the prostate and the vesicular gland that typically envelops the vas deferens in shrews (Kowalska Dyrcz, 1966; Bedford ef al., 1994) are both essential for plug formation. It is clear also that the firmly lodged copulation plug confines spermatozoa to the pericervical region of the vagina in Suncus for about $6-7 \mathrm{~h}$ after insemination, by which time spermatozoa had colonised the isthmus at or close to a maximal degree there. What, however, is the function of the plug? The plug is unlikely to represent a chastity-enforcing device, as it appears to in guinea-pigs (Martan and Shepherd, 1976), since subsequent matings displace the plug deposited at the previous ejaculation (Dryden 1969). However, after mating to prostatectomized Suncus males, the number of spermatozoa obtained from the isthmus at $25-28 \mathrm{~h}$ after ovulation was an order of magnitude below that normally recovered then, and the ampullary numbers and the fertilization rate were lower too. Moreover, the fertilizing sperm head was intact or only beginning to swell at that time, indicating that entry of spermatozoa had been delayed. Therefore, while not a sine yua non for sperm transport to the oviduct, the copulation plug formed in Suncis apparently acts to promote the establishment of an optimal isthmic population of spermatozoa - probably by maintaining a concentrated inseminate in the pericervical region of the vagina over the critical period of sperm build-up in the lower isthmus crypts.

It can be inferred from the greater number of spermatozoa in the vagina compared with the uterus, and from their individual progress through the cervical canal (Figs 5a, b), that motility is required to traverse the cervix in Suncus. The active cluster at 

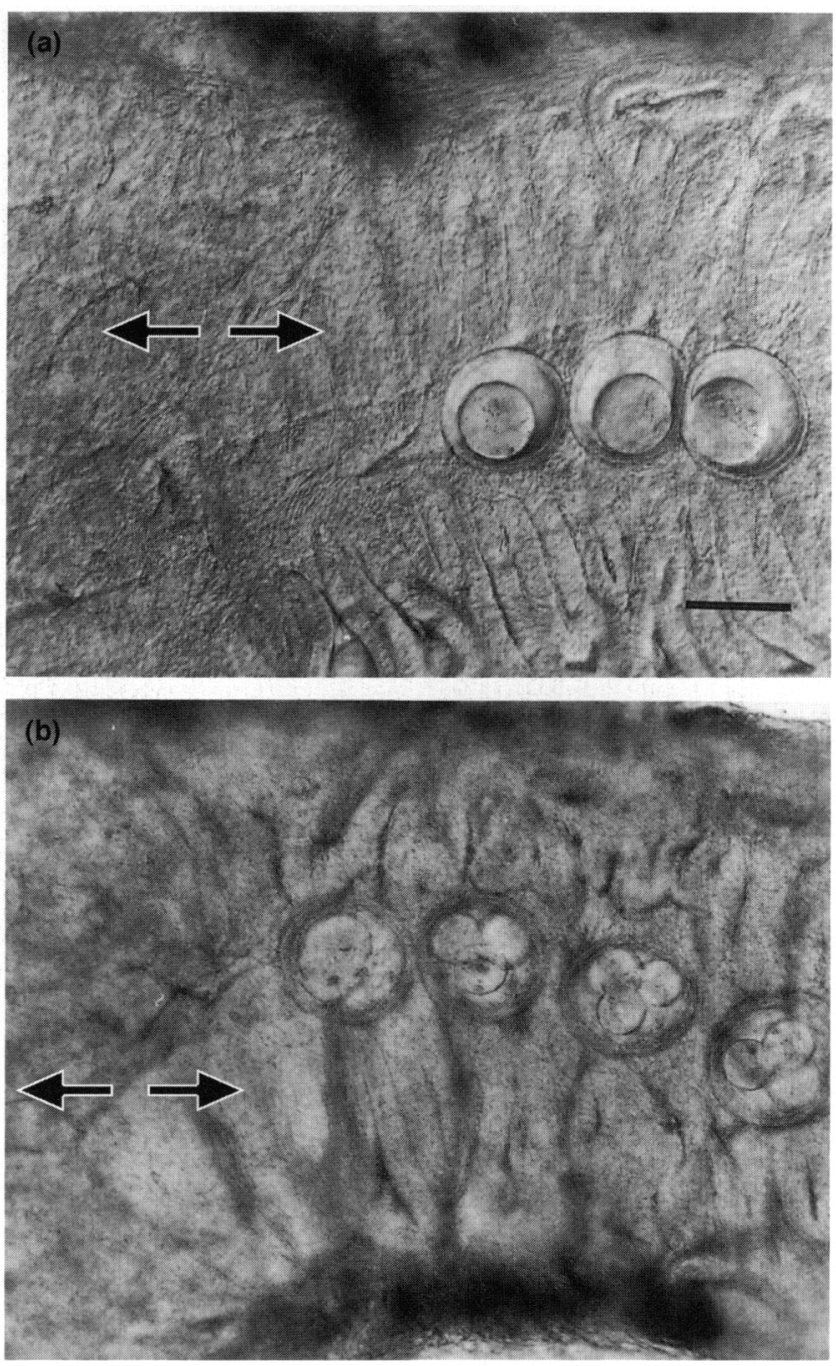

Fig. 8. (a) Unfertilized eggs, and (b) three four-cell embryos and one degenerating egg of Suncus murinus, lying distal to the isthmoampullary junction (arrows) within the upper isthmus, at $48 \mathrm{~h}$ after treatment with hCG and after mating plus hCG, respectively. The position of the eggs and embryos appeared to be stable, with no tendency for artefactual movement within either the ampulla or isthmus. Differential interference microscopy (DIC). Scale bar represents $100 \mu \mathrm{m}$.

the colliculus tubaricus (Fig. 6b) implies that individual sperm movement is needed for transport into the oviduct isthmus as well. However, the small sperm population of a few hundred observed within crypts there in Suncus contrasts with the densely packed 70000 or more that may occupy the isthmic crypts in didelphid and dasyurid marsupials (Rodger and Bedford, 1982; Bedford and Breed, 1994), and with the several thousand sequestered before ovulation in the isthmic lumen of advanced mammals, exemplified by the rabbit (Braden, 1953), mouse (Nicol and Mclaren, 1974) and hamster (Smith et al., 1987). Especially striking was the fact that so few ever reach the ampulla of Suncus after ovulation - an aspect analysed further in a companion paper (Bedford et al., 1997). In a previous study of a Guam-derived strain of Suncus murinus, occasional estimates of 25 or so were recorded in the ampulla
Table 2. The distribution of eggs or embryos within the Fallopian tube of the musk shrew, Suncus murinus

\begin{tabular}{|c|c|c|c|c|}
\hline $\begin{array}{l}\text { Time after } \\
\text { ovulation } \\
\text { (h) }\end{array}$ & $\begin{array}{c}\text { Number } \\
\text { of } \\
\text { females }\end{array}$ & Status & $\begin{array}{c}\text { Total } \\
\text { number } \\
\text { of eggs }\end{array}$ & Location \\
\hline 48 & $6^{a}$ & Unfertilized & 38 & $\begin{array}{l}47.4 \% \text { in lower ampulla } \\
52.6 \% \text { in upper isthmus }\end{array}$ \\
\hline 48 & $4^{b}$ & Most 4-cell & 24 & $\begin{array}{l}45.9 \% \text { in lower ampulla } \\
54.1 \% \text { in upper isthmus }\end{array}$ \\
\hline 85 & $7^{\mathrm{a}}$ & Unfertilized & 30 & $\begin{array}{l}70 \% \text { in lower isthmus } \\
30 \% \text { in colliculus/uterus }\end{array}$ \\
\hline 85 & $4^{b}$ & $\sim 32$-cell & 16 & $\begin{array}{l}62 \% \text { in lower isthmus } \\
38 \% \text { in colliculus/uterus }\end{array}$ \\
\hline
\end{tabular}

"hCG only.

${ }^{b}$ Mating plus hCG.

after ovulation (Bedford et al., 1994), but this number was rarely attained in the present study, according to direct counts. Paradoxically, the ipsilateral ovary had not ovulated in four of six instances when ampullary spermatozoa were found in larger numbers (range 21-87). Otherwise, only one or two spermatozoa reached the ampulla soon after ovulation, and usually not until $4 \mathrm{~h}$ or more after ovulation were there ten spermatozoa, and most of those were already moving within the cumulus as reacted cells. Since the final ampullary population was no greater if females were left with a male, or had been mated to three males, the small numbers recorded here seem to represent the biological situation for this species.

An intriguing question concerns the significance of the oviductal crypts that house spermatozoa in shrews. In Suncus some spermatozoa remained motile within isthmic crypts for more than $30 \mathrm{~h}$ after insemination, and in view of the very small number inseminated it could be that such crypts act in some way to enhance sperm 'efficiency' within the female tract. On the other hand, there are several elements that seem inconsistent with the idea that the primary function of the crypts is storage. First, their disposition varies widely according to the genus. Crypts occur in the isthmus and ampulla in Crocidura (Bedford et al., 1997a) and in Myosorex (J. M. Bedford, R. T. F. Bernard and R. M. Baxter, unpublished observations), in the ampulla alone in Cryptotis (Bedford et al., 1996b), and in Suncus here, solely in the isthmus. Second, the interval between insemination and ovulation is less than $24 \mathrm{~h}$ in the four shrew genera we have studied, obviating any apparent need for the more prolonged sperm survival seen in some marsupials that use isthmic crypts for sperm storage (Selwood and McCallum, 1987; Breed et al., 1989). Third, shrew spermatozoa are motile in oviductal crypts, according to observations with DIC optics in Suncus, Crocidura and Cryptotis. As an alternative to the idea of a storage or protective function, it is possible that such crypts act as sequestering devices in shrews, i.e. as sperm traps of possible significance for the avoidance of polyspermy. Among other Eutheria such crypts are rare at the very least. However, Hunter (1995) concluded on the basis of the sperm population sequestered by them that some 500 glands or crypts visible throughout the region of the uterotubal junction 
help to reduce the number of spermatozoa that reach the site of fertilization in the tubal ampulla of the cow. In the case of Crocidura and more so Cryptotis, many active spermatozoa were housed within ampullary crypts at the time of fertilization, but appeared to be scarce then in the adjacent crypt-free infundibulum - the fertilization site where their eggs were sequestered for some hours (Bedford et al., 1997a,b). In Suncus, by contrast, eggs did soon move down to and were fertilized in the ampulla, but it was striking that very often a total of only about ten spermatozoa ever filtered up from the isthmus throughout the period during which fertilization took place. Since late matings performed after hCG-induced ovulation show that Suncus spermatozoa can fertilize in less than $10 \mathrm{~h}$ after insemination (Bedford $\mathrm{et}$ al., 1997c), the normal delay of 6-10 h before most eggs were penetrated was therefore probably due to the limited spermatozoa at the fertilization site.

In conjunction with DIC optics and transilluminated light, the small size of the shrew oviduct makes it easy to observe the exact position of eggs and embryos within it, and so to assess the rate at which embryos are transported. In the horse (VanNiekerk and Gereneke, 1966; Betteridge and Mitchell, 1975), and the long-tongued bat Glossophaga soricina (Rasweiler, 1979), fertilized eggs may bypass unfertilized eggs within the Fallopian tube, and Ortiz et al. (1986) suggested that a differential rate of their transport occurs in hamsters. Although its short Fallopian tube compares in length with that of the bat Glossophaga, there was no such differential transport in Suncus; unfertilized eggs and growing embryos moved the same time past two definable points in the oviduct. At the time of their passage into the uterus, the growing embryos had 32 cells - a somewhat more advanced stage than in some mammals (see Harper, 1994). Thus, one must question reports of uterine entry at the 10- to 12-cell stage in Suncus (Dryden, 1969) and of viable uterine embryos at the four-cell stage in Sorex araneus (Brambell, 1935), unless there are major strain or species differences among shrews.

Certain differences between strains did emerge in relation to several reproduction-related features in Suncus murinus. Subjectively, KAT females generally displayed a greater readiness to mate than those of the OK strain, in which more prolonged pre-mating conflict was usual. The length of the Fallopian tube was also different $(6.8 \mathrm{~mm}$ in KAT versus $9.8 \mathrm{~mm}$ in $\mathrm{OK}$ ), and KAT females ovulated means of 5.0 (after mating) and 5.6 oocytes (after hCG), compared with the 3.25 oocytes produced by OK females after treatment with hCG. Moreover, the rates of unilateral ovulation after hCG were $6 \%$ for KAT and $50 \%$ for $\mathrm{OK}$ females. The lower overall and higher unilateral rates in the Okinawa strain were similar to those recorded for the colony of Dryden (Bedford et al., 1994). That was formed from stock collected on the neighbouring island of Guam, whose individuals have the body weight, grey pelage and aggressive behaviour characteristic of the OK (Okinawa) strain.

The work was performed in the Zoological Laboratory, Faculty of Agriculture, Kyushu University. The authors are very grateful to S. Shiraishi for his support, and to Y. Kawaguchi for placing the scanning electron microscope at our disposal. H. Iwamoto, Dept of Animal Sciences, made the observations on encrypted spermatozoa with the Nikon confocal microscope. J. M. Bedford was a Special Foreign
Visiting Professor under the auspices of the Japanese Ministry of Education.

\section{References}

Aronson LR and Cooper ML (1969) Mating behavior in sexually inexperienced cats after desensitization of the glans penis Animal Behavior 17 208-212

Bedford JM, Cooper GW, Phillips DM and Dryden GL (1994) Distinctive features of the gametes and reproductive tracts of the Asian Musk Shrew, Suncus murinus. Biology of Reproduction 50 820-834

Bedford JM, Phillips DM and Mover-Lev H (1996a) The novel sperm crypts and behavior of gametes in the Fallopian tube of the White-toothed shrew, Crocidura russula monacha journal of Experimental Zoology 277 262-263

Bedford JM, Mock OB and Phillips DM (1996b) The unusual ampullary sperm crypts, and behavior and role of the cumulus oophorus in the oviduct of the Least Shrew, Cryptotis parva. Biology of Reproduction 56 1255-1267

Bedford JM, Mori T and Oda S (1997) The unusual state of the cumulus oophorus and of sperm behaviour within it, in the musk shrew, Suncus murinus. Journal of Reproduction and Fertility 110 127-134

Betteridge KJ, and Mitchell D (1972) A surgical technique applied to the study of tubal eggs in the mare Journal of Reproduction and Fertility Supplement $\mathbf{2 3}$ $519-524$

Braden AWH (1953) Distribution of sperm in the genital tract of the female rabbit after coitus Australian Journal of Biological Science 6 693-705

Brambell FWR (1935) Reproduction in the common shrew (Sorex araneus Linnaeus). I. The oestrous cycle of the female Philosophical Transactions of the Royal Society B 225 1-49

Breed WG, Leigh CM and Bennett JH (1989) Sperm morphology and storage in the female reproductive tract of the fat-tailed dunnart, Sminthopsis crassicaudata (Marsupialia:Dasyuridae) Gamete Research 23 61-75

Carroll, RL (1988) Vertebrate Paleontology and Evolution Freeman \& Co., New York

Clenendon AL and Rissman EF (1990) Prolonged copulatory behavior facilitates pregnancy success in the musk shrew Hormones and Behavior 25 125-127

Dryden GL (1969) Reproduction in Suncus murinus. Journal of Reproduction and Fertility Supplement 6 377-396

Dryden GL (1975) Establishment and maintenance of shrew colonies International Zoo Yearbook 15 12-18

Harper MJK (1994) Gamete and zygote transport. In The Physiology of Reproduction (2nd Edn) pp 123-187 Eds E Knobil and JD Neill. Raven Press, New York

Hunter RHF (1995) Significance of the epithelial crypts at the bovine uterotubal junction in the pre-ovulatory phase of sperm regulation Acta Veterinaria Scandinavica 36 413-421

Kitoh J, Ota K, Yamashita K, Sugiura Y, Hirunagi K, Orita S and Oda S (1985) The urogenital organs. In Suncus murinus - Biology of the Laboratory Shrew pP 239-258 Eds S Oda, J Kitoh, K Ota and G Isomura. Japan Scientific Societies Press (JSSP) Tokyo (in Japanese)

Kowalska-Dyrcz A (1966) A comparative study of the male genital tract in some species of shrews Acta Theriologica $1171-127$

Krutzsch PH and Crichton E (1987) Reproductive biology of the Little Mastiff Bat, Monopterus planiceps (Chiroptera: Molossidae) in South-east Australia American Journal of Anatomy 178 352-368

Martan J and Shepherd BA (1976) Role of copulatory plug in reproduction of guinea pig Journal of Experimental Zoology 196 79-84

Milligan SR (1982) lnduced ovulation in mammals Oxford Reviews of Reproductive Biology 4 1-46

Murthy KVR and Vamburker SA (1978) Studies on the male genitalia of Indian Bats Part II Male genitalia of the Giant Indian Fruit Bat Pteropus giganteus giganteus (Brunnich) Journal of the Zoological Society of India 30 47-55

Nicol A and McLaren A (1974) An effect of the female genotype on sperm transport in mice Journal of Reproduction and Fertility 39 421-424

Ortiz ME, Bedregal P, Carvajal MI and Croxatto HB (1986) Fertilized and unfertilized ova are transported at different rates by the hamster oviduct Biology of Reproduction 34 777-781

Parkes AS (1960) The biology of spermatozoa and artificial insemination. In Marshall's Physiology of Reproduction (3rd Edn) Vol. 1 part $2 \mathrm{pp} 161-263$. Ed. AS Parkes. Longmans, London

Rasweiler J] (1979) Differential transport of embryos and degenerating ova by oviducts of the long-tongued bat, Glossophaga soricina. Journal of Reproduction and Fertility 55 329-334 
Rissman EF (1987) Social variables influence female sexual behavior in the musk shrew (Suncus murinus) Joumal of Comparative Psychology 101 3-6

Rodger JC and Bedford JM (1982) Induction of oestrus, recovery of gametes, and the timing of fertilization events in the opossum, Didelphis virginiana. Journal of Reproduction and Fertility 64 159-169

Sachs B, Glater GB and O'Hanlon TK (1984) Morphology of the erect glans penis in rats under various gonadal hormone conditions Anatomical Record $21045-52$

Selwood L and McCallum F (1987) Relationship between longevity of spermatozoa after insemination and the percentage of normal embryos in brown marsupial mice (Antechinus stuartii) (Dasyuridae) Journal of Reproduction and Fertility 79 495-503

Smith TT, Koyanagi F and Yanagimachi R (1987) Distribution and number of spermatozoa in the oviduct of the golden hamster after natural mating and artificial insemination Biology of Reproduction 37 225-234

VanNiekerk CH, and Gerneke WH (1966) Persistence and parthenogenetic cleavage of tubal ova in the mare Onderstepoort Journal of Veterinary Research 31 195-232

Zarrow MX and Clark JH (1968) Ovulation following vaginal stimulation in a spontaneous ovulator and its implications Journal of Endocrinology $\mathbf{4 0}$ 343-352 